\title{
BMJ Open Sexually transmitted infections in young people and factors associated with HIV coinfection: an observational study in a large city
}

\author{
Alexis Sentís, ${ }^{1}$ Mario Martin-Sanchez, ${ }^{\oplus 1,2}$ Maider Arando, ${ }^{3}$ Martí Vall, ${ }^{3}$ \\ María Jesus Barbera, ${ }^{3}$ Inma Ocaña, ${ }^{3}$ Ana González Cordón, ${ }^{4}$ Mercè Alsina, ${ }^{4}$ \\ Gemma Martin-Ezquerra, ${ }^{5}$ Hernando Knobel, ${ }^{5}$ Mercè Gurguí, ${ }^{6}$ Alvaro Vives, ${ }^{7}$ \\ Josep Coll, ${ }^{8}$ Joan Artur Caylà, ${ }^{1,9,10}$ Patricia Garcia de Olalla, ${ }^{1,9}$ and STI-HIV group \\ of Barcelona
}

To cite: Sentís A, MartinSanchez M, Arando M, et al. Sexually transmitted infections in young people and factors associated with HIV coinfection: an observational study in a large city. BMJ Open 2019:9:e027245. doi:10.1136/ bmjopen-2018-027245

- Prepublication history for this paper is available online. To view these files, please visit the journal online (http://dx.doi. org/10.1136/bmjopen-2018027245).

Received 19 0ctober 2018 Revised 9 January 2019 Accepted 27 February 2019

Check for updates

(c) Author(s) (or their employer(s)) 2019. Re-use permitted under CC BY-NC. No commercial re-use. See rights and permissions. Published by BMJ.

For numbered affiliations see end of article.

Correspondence to Dr Patricia Garcia de Olalla; polalla@aspb.cat

\section{ABSTRACT}

Objectives Young people are a critical target group for sexually transmitted infections (STI) surveillance due to their particular behavioural and social related vulnerability. The aim of this study was to describe the epidemiological characteristics and trends in the incidence of gonorrhoea, syphilis, HIV and venereal lymphogranuloma (LGV) among 15-24-year-olds in Barcelona, and to determine factors associated with HIV coinfection.

Design We performed a population-based incidence study covering the 2007-2015 period.

Participants All new cases of STI-HIV, gonorrhoea, infectious syphilis and LGV_-notified to the epidemiological surveillance system in Barcelona between 2007 and 2015. 1218 cases were studied: $84.6 \%$ were men, $19.3 \%$ were $15-19$ years old and $50.6 \%$ were born in Spain. Among men, $73.7 \%$ were men who have sex with men (MSM); among women, $85.6 \%$ were women that have sex with men.

Primary and secondary outcomes Incidence of HIV, gonorrhoea, infectious syphilis and LGV. HIV coinfection. Results There was an increase in the incidence of gonorrhoea, from 1.9 cases per 10000 people in 2007 to $7.6 / 10000$ in $2015(p<0.01)$, in MSM from 27.1 to $228.8 / 10000(p<0.01)$. The incidence of syphilis increased from $0.4 / 10000$ in 2007 to $3.1 / 10000$ in 2015 (significant in men only, $p<0.01$ ), in MSM from 18.1 to $116.9 / 10000(p<0.01)$. The incidence of HIV showed a non-significant increase in men $(p=0.27)$, and that of LGV remained stable $(p=0.59)$. Factors associated with increased risk of HIV coinfection included being MSM (adjusted OR[ORa]=14.14, 95\% Cl 3.34 to 59.91) and having $>10$ sexual partners $(\mathrm{ORa}=4.11,95 \% \mathrm{Cl} 1.53$ to 11.01) or STI diagnosis during the previous 12 months (ORa=2.06; $95 \% \mathrm{Cl} 1.13$ to 3.77 ).

Conclusions The incidence of gonorrhoea and syphilis among 15-24-year-olds increased, while HIV infection remained stable but with a high incidence among MSM. Being MSM, having sex with multiple partners and having a diagnosis of an STI in the previous 12 months were factors associated with HIV coinfection.

\section{Strengths and limitations of this study}

- A population-based sexually transmitted infection (STI) incidence study in young people from a large city with a robust STI surveillance system. The use of logistic regression models allowed us to disentangle factors associated with HIV coinfection.

- The inclusion of sociodemographic, clinical and behavioural variables permitted a strong description and analysis of the results.

- For some variables, the proportion of missing values was high. Nonetheless, we have included a missing category in all variables, such that all cases are considered in the models.

- The lack of data about other STI, since they were not mandatory notification diseases, may mean a loss of valuable information regarding the analysis of STI impact in a large city.

\section{INTRODUCTION}

With more than one million acquired infections per day worldwide, sexually transmitted infections (STI) remain one of the most common acute illnesses globally. ${ }^{1}$ Although trend data can be influenced by heterogeneous reporting and differences between healthcare systems, during the last decade, there has been a clear overall increase in the incidence of Chlamydia trachomatis, gonorrhoea, syphilis and venereal lymphogranuloma (LGV) in Europe, including Spain. ${ }^{2} 3$ In contrast, there has been a steady decline in HIV incidence in recent years. ${ }^{45} \mathrm{~A}$ recent study based in Barcelona reported an increase in the number of STI cases, mainly in men who had sex with men (MSM) with university-level education. ${ }^{6}$

In 2013 in Europe, young people and MSM were the most vulnerable groups for 
STI acquisition. People aged 15-24 years accounted for two-thirds of all cases of C. trachomatis and 39\% of all cases of gonorrhoea. ${ }^{2}$ Adolescents and young people are a critical target group for STI surveillance because they are vulnerable for various reasons, mostly related to behaviour and social factors, ${ }^{78}$ and also because many young people at risk of STI are not properly screened. ${ }^{910}$ Special emphasis must be placed on HIV because STI carriers have an increased risk of HIV infection ${ }^{11}$ and adolescents infected with HIV are more likely to acquire other STI infections. ${ }^{712}$

The main aim of this study was to describe the epidemiological characteristics and trends in the incidence of HIV infection, gonorrhoea, syphilis and LGV among young people in a large city. In addition, we assessed whether HIV status was associated with prevalent risk factors among young people with gonorrhoea, syphilis or LGV.

\section{METHODS}

\section{Study design and participants}

This is a population-based incidence study of all new cases of sexually transmitted HIV, gonorrhoea, syphilis and LGV infection notified to the epidemiological surveillance system in Barcelona city using case definitions established following the European standards. ${ }^{13}$ The target population was young people aged 15-24 years who were residents in Barcelona and diagnosed between January 2007 and December 2015 (total population of the city on 30 June 2015 was 1604550 , of which 141.363 $(8.8 \%)$ were aged $15-24$ years $\left.^{14}\right)$. Cases of congenital, late latent and tertiary syphilis were excluded from the study, as were cases of AIDS or cases of HIV infection in intravenous drug user or due to vertical transmission.

\section{Variables}

We analysed sociodemographic variables: sex, country of birth, educational level and age (in two categories, 15-19 and 20-24 years, in line with the most common uses by Centers for Disease Control and Prevention ${ }^{15}$ and $\mathrm{WHO}^{1}$ ). Clinical variables: STI diagnosis in the previous 12 months and coinfection with HIV. Behavioural variables: number of sexual partners in the previous 12 months, use of condom in most recent sexual contact and sexual behaviour, categorised separately for men and women as follows. Men (three groups): MSM, including transgender women and bisexual men; men who have sex with women only (MSW); and unknown sexual behaviour. Women (three groups): women who have sex with men (WSM), including bisexual and heterosexual, women who have sex with women (WSW) and unknown sexual behaviour. In the regression models, due to the small numbers of WSW, we only used one category, 'women'.

\section{Statistical analyses}

A descriptive analysis of the epidemiological characteristics of all new cases of STI-HIV, gonorrhoea, syphilis and
LGV infections-was carried out. We calculated annual incidence rates per 10000 inhabitants, stratified by sex and sexual behaviour category. Sex-specific rates were estimated based on population data from the Barcelona municipal census for each year of study ${ }^{14}$; rates for the various categories of sexual behaviour were estimated based on data from the 2011 Barcelona Health Interview Survey. ${ }^{16}$ Incidence trends were analysed using the $\chi^{2}$ test for linear trend.

We examined risk factors associated with HIV coinfection, prevalent HIV cases during the study period, among persons diagnosed with gonorrhoea, syphilis or LGV. In persons with more than one STI, only the last diagnosed event was included. First, we fit bivariate logistic regression models to assess the association between positive HIV diagnosis as a dependent variable and each of the potential risk factors mentioned above. Second, potential risk factors that showed a statistically significant association with HIV diagnosis were included in multivariable logistic regression models, along with variables for education and country of birth, which are thought to be important regardless of whether or not they showed a statistically significant association in the bivariate analysis. ${ }^{6}$

Odds ratios (OR) and its 95\% confidence intervals (CI) were estimated. All analyses were performed using STATA (V.13; Stata Corporation, College Station, Texas, USA).

\section{Ethical considerations}

In Barcelona city, surveillance of obligatory notifiable diseases is provided by the Barcelona Public Health Agency (ASPB). In compliance with article 13 of law 67/2010 (25 May 2010) of the Health Department of Generalitat de Catalunya, nominal notification of cases of gonorrhoea, syphilis and LGV has been obligatory since 2007. Notification of HIV cases was voluntary between 2001 and July 2010, and obligatory and nominal thereafter. ${ }^{17}$

Data confidentiality and other ethical considerations were handled according the international recommendations,${ }^{18}$ the Helsinki Declaration revised by the World Medical Organization in Fortaleza in 2013 and Spanish Law 15/1999 on Data Protection. Patient information was anonymised and deidentified prior to analysis and therefore no informed consent was required.

\section{Patient and public involvement statement}

Patients were not directly involved in this study; only data coming from notifiable disease surveillance systems were used.

\section{RESULTS}

Sociodemographic, clinical and behavioural characteristics of the population

This study included 1218 cases of STI, affecting 1139 persons, $187(15.4 \%)$ of the cases were women, 235 (19.3\%) were aged $15-19$ years and $574(47.1 \%)$ were born in Spain. Of the 1031 men, $62.1 \%$ were MSM and 22.2\% were MSW. Of the 187 women, 160 (85.6\%) were 
WSM, of whom 15 were bisexual women; two of them were diagnosed with syphilis, three with gonorrhoea and ten with HIV.

The most common infection was gonorrhoea $(51.9 \%$, $\mathrm{n}=632)$, followed by HIV (25.4\%, $\mathrm{n}=309)$ and syphilis (21.8\%, $\mathrm{n}=266)$, while LGV was the least common infection with just 11 cases among MSM. Women accounted for $19.6 \%$ of cases of gonorrhoea, $11.7 \%$ of syphilis and $10.4 \%$ of HIV. The proportion of MSM among HIV cases was $84.8 \%(\mathrm{n}=235), 71.5 \%$ for syphilis and $44.5 \%$ gonorrhoea (table 1).

Among cases of gonorrhoea and syphilis, men and women differed in terms of the number of sexual partners $(p<0.01)$, with woman having significantly fewer partners than men (table 1). Also, for cases of gonorrhoea, the younger group (15-19 years) had a higher proportion of women (36.3\%, vs $21.5 \%$ for men); women had lower proportion of university education and had a higher proportion of condom use $(\mathrm{p}<0.05)$ (table 1$)$.

Sixty-two persons presented reinfections during the study period, resulting in 141 cases $(11.6 \%$ of the total number of cases). Of those persons, 50 had two infections, eight had three, three had four and one person had five infections. The most common pattern was two consecutive gonorrhoea infections (affecting 18 persons), followed by a diagnosis of syphilis and subsequently gonorrhoea (affecting 10 persons).

\section{Incidence and trends in incidence}

The incidence of HIV decreased from 1.6/10 000 in 2007 to $0.5 / 10000$ in 2015. A non-significant statistical increase was observed in men $(p=0.27)$. However, in more recent years, there has been a slightly decreasing tendency in MSM (141.5 cases per 10000 people in 2013, and 131.5 in 2015) (figure 1).

The incidence of gonorrhoea increased from $1.9 / 10000$ in 2007 to $7.6 / 10000$ in 2015 ( $\mathrm{p}<0.01)$. This increase was observed in both men and women (figure 2). Regarding sexual behaviour, the increase in incidence of gonorrhoea was statically significant in all three categories analysed $(\mathrm{p}<0.01)$, with higher incidence rates in MSM (27.1/10 000 in 2007 and 228.8/10 000 in 2015) (figure 2). The incidence of syphilis increased from $0.4 / 10000$ in 2007 to $3.1 / 10000$ in 2015, though this was only statistically significant in men $(\mathrm{p}<0.01)$ (figure 2$)$. Regarding sexual behaviour, the increase of syphilis was statistically significant in MSM and MSW $(\mathrm{p}<0.01)$, with higher incidence for MSM (18.1/10 000 in 2007 and $116.9 / 10000$ in 2015) (figure 2). Finally, the incidence of LGV remained stable throughout the study period $(\mathrm{p}=0.59)$.

\section{HIV COINFECTION}

In the descriptive analysis of the HIV coinfection for each STI, we observed statistically significant differences between men and women. Among cases of gonorrhoea and syphilis, the proportion of HIV coinfection was $7.7 \%$ in men and $1.6 \%$ in women $(\mathrm{p}=0.01)$ and $16.6 \%$ of men and $0 \%$ of women, respectively. Among men, the highest rate of HIV coinfection was observed among LGV cases $(63.6 \%)$.

We also observed statistically significant differences in the proportion of HIV coinfection in gonorrhoea and syphilis when stratifying by (1) sexual behaviour $(75.6 \%$ and $89.7 \%$ of cases of gonorrhoea and syphilis with HIV coinfection, respectively, were MSM; $\mathrm{p}<0.01$ in both cases), (2) number of sexual partners the previous 12 months $(36.6 \%$ and $35.9 \%$ of cases of gonorrhoea and syphilis with HIV coinfection, respectively, had $\geq 10$ sexual partners; $p<0.01$ in both cases), (3) STI diagnoses during the previous 12 months $(41.5 \%$ and $28.2 \%$ of cases of gonorrhoea and syphilis, respectively, were previously diagnosed with HIV coinfection, compared with $14.04 \%$ and $12.3 \%$ with a non-HIV coinfection; $\mathrm{p}<0.01$ in both cases). Among cases of gonorrhoea, but not syphilis, the proportion of HIV coinfection varied significantly between age categories $(90.2 \%$ of cases of HIV coinfection were aged 20-24 years, compared with $74.6 \%$ among cases of non-HIV coinfection). Among cases of syphilis, the proportion of HIV coinfection varied significantly according to country of birth $(46.1 \%$ of cases of HIV coinfection were people born in Latin America, compared with $22 \%$ of cases of non-HIV coinfection).

To identify risk factors associated with HIV coinfection, we analysed only one STI per person as it is mentioned in methods. 830 patients with gonorrhoea, syphilis or LGV were included and we found that the following variable categories were associated with increased risk of HIV coinfection: being MSM (ORa: 14.14, 95\% CI 3.34 to 59.91 ), having $\geq 10$ sexual partners during the previous 12 months $(\mathrm{ORa}=4.11,95 \%$ CI 1.53 to 11.01$)$ and having a previous diagnosis of STI during the previous 12 months (ORa=2.06; 95\% CI 1.13 to 3.77) (table 2).

\section{DISCUSSION}

In this study of people aged 15-24 years residing in Barcelona city, we observed a significant increase in the incidence of gonorrhoea and syphilis in men, especially in MSM, and of gonorrhoea in women. In young people, being MSM, having 10 or more sexual partners or a previous diagnosis of STIs during the previous year showed an increased risk of HIV coinfection.

Previous studies have found that new STI diagnoses in 15-24-year-olds account for half of all new cases of STI in the USA, ${ }^{7}$ and more than a half of those worldwide, ${ }^{19}$ even though this age group represents only $\sim 25 \%$ of the sexually active population. ${ }^{715}$ In Europe, this group of people account for 5\%,13\% and 35\% of all reported cases of LGV, syphilis and gonorrhoea, respectively. ${ }^{20-22}$ In Barcelona, this proportion was $3 \%, 8 \%$ and $18 \%$, respectively. ${ }^{23}$ Usually, higher STI rates have been described in large cities or urban areas where vulnerable populations are found more concentrated. ${ }^{24} 25$ 
Table 1 Distribution of sociodemographic, clinical and behavioural characteristics in cases of HIV, gonorrhoea, syphilis or venereal lymphogranuloma (LGV) in 15-24-year-olds in Barcelona, 2007-2015

\begin{tabular}{|c|c|c|c|c|c|c|c|}
\hline & \multicolumn{2}{|l|}{ HIV } & \multicolumn{2}{|c|}{ Gonorrhoea } & \multicolumn{2}{|l|}{ Syphilis } & \multirow{2}{*}{$\frac{\text { LGV }}{\text { Men }}$} \\
\hline & Men & Women & Men & Women & Men & Women & \\
\hline & $\mathbf{N}(\%)$ & $\mathbf{N}(\%)$ & $\mathbf{N}(\%)$ & $\mathbf{N}(\%)$ & $\mathbf{N}(\%)$ & $\mathbf{N}(\%)$ & $\mathbf{N}(\%)$ \\
\hline Total cases & 277 (100) & $32(100)$ & $508(100)$ & $124(100)$ & $235(100)$ & $31(100)$ & $11(100)$ \\
\hline \multicolumn{8}{|l|}{ Age group } \\
\hline $15-19$ & $36(13.0)$ & 7 (21.9) & $109(21.5)$ & 45 (36.3) & $31(13.2)$ & $6(19.4)$ & $1(9.1)$ \\
\hline $20-24$ & $241(87.0)$ & $25(78.1)$ & 399 (78.5) & $79(63.7)$ & $204(86.8)$ & 25 (80.6) & $10(90.9)$ \\
\hline \multicolumn{8}{|l|}{ Education level } \\
\hline University & 35 (12.6) & $1(3.1)$ & 83 (16.3) & $13(10.5)$ & 35 (14.9) & $7(22.6)$ & $3(9.1)$ \\
\hline Secondary & $118(42.6)$ & $11(34.4)$ & $131(25.8)$ & $44(35.5)$ & $63(26.8)$ & $10(32.3)$ & $7(63.6)$ \\
\hline Primary or less & $25(9.0)$ & 7 (21.9) & $64(12.6)$ & 25 (20.2) & $57(24.3)$ & $7(22.6)$ & $1(9.1)$ \\
\hline Missing & $99(35.7)$ & $13(40.6)$ & $230(45.3)$ & 42 (33.9) & $80(34.0)$ & $7(22.69$ & 0 \\
\hline \multicolumn{8}{|l|}{ Country of birth } \\
\hline Spain & $129(46.6)$ & $8(25.0)$ & $249(49.0)$ & $59(47.6)$ & $113(48.1)$ & $10(32.3)$ & $6(54.5)$ \\
\hline Western countries* & $15(5.4)$ & 0 & $46(9.1)$ & $7(5.7)$ & $18(7.7)$ & 0 & $1(9.1)$ \\
\hline Latin America & $104(37.6)$ & $15(46.9)$ & $129(25.4)$ & $34(27.4)$ & $58(24.7)$ & $10(32.3)$ & $4(36.4)$ \\
\hline Eastern Europe & $10(3.6)$ & $2(6.3)$ & $15(2.9)$ & $7(5.7)$ & $7(3.0)$ & $5(16.1)$ & 0 \\
\hline Other & $18(6.5)$ & 7 (21.9) & $24(4.7)$ & $2(1.6)$ & $19(8.1)$ & $4(12.9)$ & 0 \\
\hline Missing & $1(0.4)$ & 0 & $45(8.9)$ & $15(12.1)$ & $20(8.5)$ & $2(6.5)$ & 0 \\
\hline \multicolumn{8}{|l|}{ Sexual behaviour } \\
\hline MSW & 32 (11.6) & na & 160 (31.5) & na & 37 (15.7) & na & 0 \\
\hline MSM & $235(84.8)$ & na & $226(44.5)$ & na & $168(71.5)$ & na & $11(100)$ \\
\hline WSM & na & $32(100) \dagger$ & na & $105(84.7) \ddagger$ & na & $23(74.2) \S$ & na \\
\hline Missing & $10(3.6)$ & 0 & $122(24.0)$ & $19(15.3)$ & 30 (12.8) & $8(25.8)$ & 0 \\
\hline \multicolumn{8}{|c|}{ STI diagnoses in the previous 12 months } \\
\hline No & 251 (90.6) & $31(96.9)$ & $427(84.0)$ & $105(84.7)$ & $199(84.7)$ & $28(90.3)$ & $6(54.5)$ \\
\hline Yes & $26(9.4)$ & $1(3.1)$ & $81(15.9)$ & $19(15.3)$ & $36(15.3)$ & $3(9.7)$ & $5(45.5)$ \\
\hline \multicolumn{8}{|c|}{ Number of sexual partners in the previous 12 months } \\
\hline 1 to 3 & na & na & $107(21.1)$ & $60(48.4)$ & $36(15.3)$ & $12(38.7)$ & $1(9.1)$ \\
\hline 4 to 6 & na & na & $39(7.7)$ & $11(8.9)$ & $14(6.0)$ & 0 & 0 \\
\hline 7 to 10 & na & na & $29(5.7)$ & $6(4.8)$ & $25(10.6)$ & $2(6.5)$ & $1(9.1)$ \\
\hline$>10$ & na & na & 69 (13.6) & $3(2.4)$ & $44(18.7)$ & $0(0.0)$ & $6(54.6)$ \\
\hline Missing & na & na & 264 (52.0) & $44(35.5)$ & $116(49.4)$ & $17(54,8)$ & $3(27.3)$ \\
\hline \multicolumn{8}{|l|}{ HIV coinfection } \\
\hline No & na & na & 469 (92.3) & $122(98.4)$ & $196(83.4)$ & $31(100)$ & $4(36.4)$ \\
\hline Yes & na & na & $39(7.7)$ & $2(1.6)$ & 39 (16.6) & 0 & $7(63.6)$ \\
\hline \multicolumn{8}{|l|}{ Condom use } \\
\hline Yes & na & na & $73(14.4)$ & $29(23.4)$ & $47(20.0)$ & $4(12.9)$ & $3(27.3)$ \\
\hline No & na & na & $253(49.8)$ & $67(54,0)$ & $103(43.8)$ & $13(41.9)$ & 7 (63.6) \\
\hline Missing & na & na & $182(35.8)$ & 28 (22.6) & 85 (36.2) & 14 (45.2) & $1(9.1)$ \\
\hline
\end{tabular}

*Western countries: Western Europe, USA, Canada and Australia.

$\dagger 10$ women were bisexual.

$\ddagger$ Three women were bisexual.

$\S$ Two women were bisexual.

na, not applicable; MSM, men that have sex with men; MSW, menthat have sex only with women; STI, sexually transmitted infection; WSM,

women who have sex with men. 
a) HIV in MSM

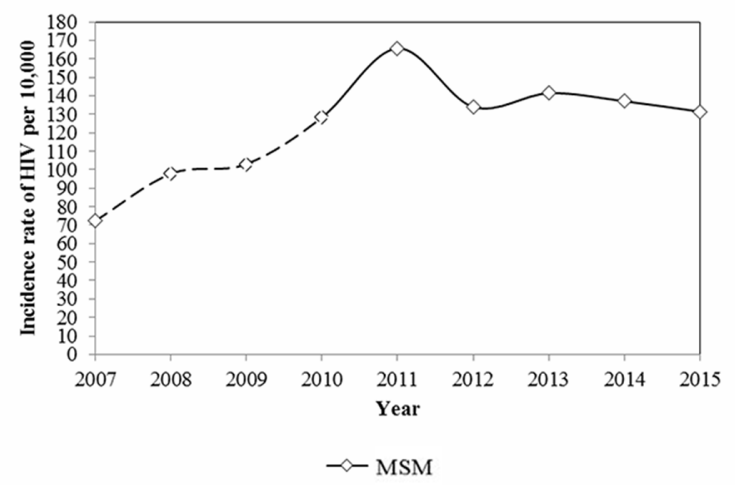

b) HIV in men MSW and women

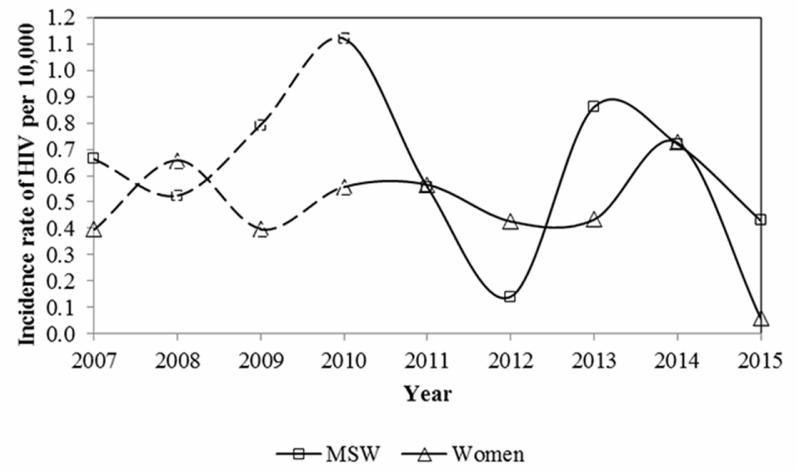

Figure 1 Incidence in people between 15 and 24 years of: HIV in MSM (men who had sex with men) (a), MSW (men who have sex with women only) (b) and in women (b) per $10000 \mathrm{MSM} / \mathrm{MSW} /$ women. The dashed line indicates that HIV cases were subject to voluntary notification from 2007 to 2009, and obligatory and nominal notification thereafter.

To our knowledge, few studies have analysed trends in the incidence of STIs in 15-24-year-olds. For instance, in recent years, it has been observed an increase in the incidence of cases of STI among people under 20 years old in Ireland ${ }^{26}$ and in 15-24-years old in the UK. ${ }^{24} 27$ In this study, we observed an increase in the incidence in 15-24-year-olds in Barcelona. We want to remark that, although there was not any massive campaign or specific community project to increase STI detection or notification in Barcelona, the recent introduction of PCR for gonorrhea diagnosis may have improved the surveillance system sensitivity. Besides, STI surveillance has been a priority for ASPB even before 2007 when gonorrhoea,

a) Gonorrhoea in MSM

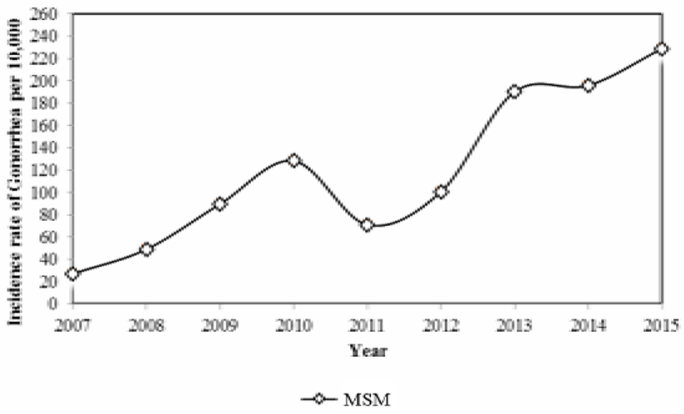

c) Syphilis in MSM



$\neg \mathrm{MSM}$ syphilis and LGV were declared mandatory notifiable diseases in Catalonia. ${ }^{17}$ In spite of this, we believe that last year's observed increase specifically in Spain but also in all the European region, ${ }^{2}{ }^{26}$ mostly in large cities, is likely to be a real increase on the incidence and not only due because of an improvement on the surveillance system sensitivity or other related issues.

Moreover, the incidence of STI was higher among women, ${ }^{9}{ }^{28} \mathrm{MSM}^{19}{ }^{29}$ and younger people, highlighting them as especially vulnerable populations. Our results show that MSM are a risk group for the STIs analysed, mainly for HIV, syphilis and LGV. In fact, we found that young MSM sometimes show up to 20-fold higher

b) Gonorrhoea in men MSW and women

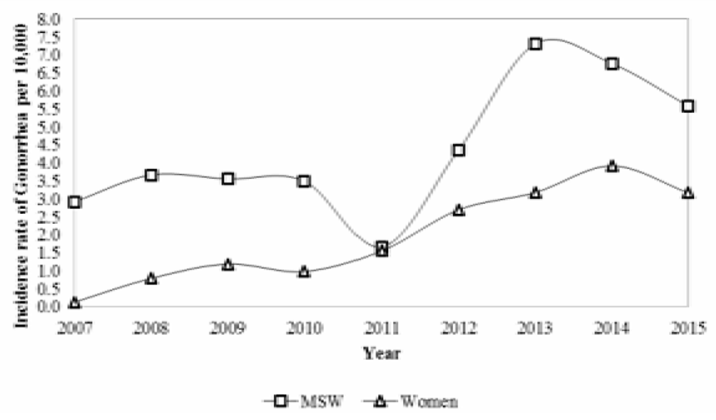

d) Syphilis in men MSW and women

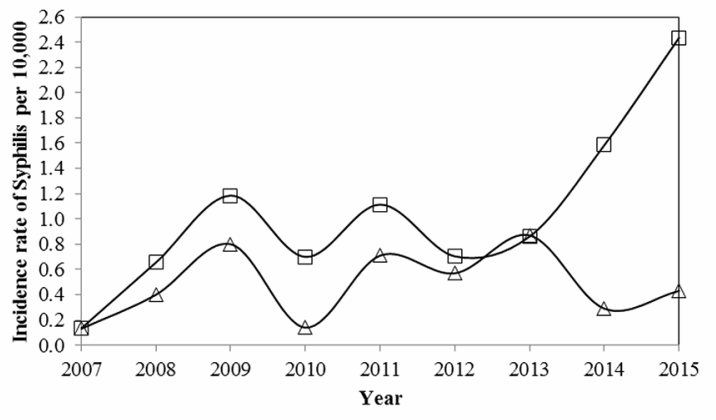

$\sqsubset$ MSW $\triangle$ Women

Figure 2 Incidence in people between 15 and 24 years of: gonorrhoea and syphilis in men who had sex with men (MSM) $(a, c)$, men who have sex with women only $(M S W)(b, d)$ and in women $(b, d)$ per 10000 MSM/MSW/women. 
Table 2 Associated factors to HIV coinfection in 15-24-year-old patients diagnosed of gonorrhoea, syphilis or venereal lymphogranuloma in Barcelona ( $\mathrm{N}=830)$

\begin{tabular}{|c|c|c|}
\hline Variables & ORa* & $95 \% \mathrm{Cl}$ \\
\hline \multicolumn{3}{|l|}{ Age } \\
\hline Each more 1 year & 1.13 & 0.96 to 1.28 \\
\hline \multicolumn{3}{|l|}{ Education } \\
\hline Secondary or university & 1.00 & \\
\hline Primary or less & 1.03 & 0.47 to 2.26 \\
\hline Missing & 0.95 & 0.49 to 1.84 \\
\hline \multicolumn{3}{|l|}{ Country of birth } \\
\hline Spain & 1.00 & \\
\hline Not Spain & 1.37 & 0.79 to 2.38 \\
\hline Missing & 1.01 & 0.35 to 2.90 \\
\hline \multicolumn{3}{|l|}{ Sexual behaviour } \\
\hline MSW & 1.00 & \\
\hline MSM & 14.14 & 3.34 to 59.91 \\
\hline Missing (men) & 4.91 & 0.96 to 25.13 \\
\hline Women & 1.40 & 0.19 to 10.12 \\
\hline \multicolumn{3}{|c|}{ STI diagnoses in the previous 12 months } \\
\hline No & 1.00 & \\
\hline Yes & 2.06 & 1.13 to 3.77 \\
\hline \multicolumn{3}{|c|}{ Number of sexual partners in the previous 12 months } \\
\hline One to three & 1.00 & \\
\hline Four to six & 1.33 & 0.34 to 5.16 \\
\hline Seven to ten & 0.89 & 0.21 to 3.84 \\
\hline$>10$ & 4.11 & 1.53 to 11.01 \\
\hline Missing & 2.33 & 0.89 to 6.10 \\
\hline
\end{tabular}

*This model was adjusted for all the listed variables in the table: Age, education, country of birth, sexual behaviour, previous 12 months STI diagnoses and number of sexual partners (last 12 months).

MSM, men who have sex with men; MSW, men who have sex with women only; ORa, adjusted odds ratio ; STI, sexually transmitted infection.

increase in incidence and magnitude than MSW or women. Several studies indicate a low incidence of gonorrhoea observed among women due to the difficulties to reach them. ${ }^{98}{ }^{30}$ Despite this, we also found that, among women diagnosed with gonorrhoea, the proportion of 15-19-year-olds was approximately 50\% higher than that among men. In fact, we found that the incidence of gonorrhoea differed between men and women according to educational level, which may be due to the younger age of the female cases. These observations underline the need to put special emphasis and efforts in the youngest women. The increasing trends may also be partly due to improved coverage of epidemiological surveillance programmes, and the broader availability of more sensitive diagnostic tests. ${ }^{20-22}$
We stress the importance of improving programmes and interventions targeting STIs in young people. In some countries, STIs are mainly detected by general practitioners; however, specialised STI centres ${ }^{31}$ have been shown to be more effective in diagnosing STI such as chlamydia, gonorrhoea and syphilis, especially among young men. In Barcelona in recent years, specialised STI centres have diagnosed approximately $40 \%$ of all cases of gonorrhoea (unpublished data).

Given the higher risk of HIV coinfection among young MSM also observed in the multivariate analysis and the reported increase in incidence of syphilis and gonorrhoea also in young MSM, we must remain alert to a possible increase in the incidence of HIV in this group; but as in other studies and reports, ${ }^{4}$ our HIV results cannot corroborate this possibility at present. In fact, our results show a statistically non-significant decrease in incidence of HIV in MSM in the last few years. Moreover, HIV carriers are vulnerable to new STIs, especially MSM, ${ }^{32}$ young people ${ }^{712}$ and those who had a previous history of STI. ${ }^{32}$ Also, the greater risk associated with a higher number of sexual partners found in the multivariate analysis is consistent with previous reports. ${ }^{726}$ In light of our results, young MSM as well as young people with a high number of sexual partners or a previous diagnosis of STIs have a higher risk of acquiring HIV, which could make them potential candidates for HIV Pre-Exposure Prophylaxis (PrEP). The use of PrEP along with promotion of condom use and adherence support could be considered in young people in specific situations as some guidelines are already recommending. ${ }^{33}$

A limitation of our study is that, for some variables, the proportion of missing values was high. Nonetheless, we have included a missing category in all variables, such that all cases are considered in the models, allowing us to disentangle the direction and magnitude of association with HIV coinfection for the missing category. Also, we have to mention that we could not study chlamydial infection since, in Barcelona, this infection, probably the most frequent in young people, has been nominal notifiable since 2016 .

We also stress the importance of continued efforts to develop effective interventions for STI prevention and control among young people. Screening programmes, brief behavioural counselling and partner notification often work well, depending on the setting where they are implemented, which is an important factor when designing such interventions. ${ }^{34}$

In conclusion, the incidence of gonorrhoea and syphilis among 15-24-year-olds has increased in Barcelona in recent years, especially in MSM, while HIV infection remains stable but with a high incidence among MSM. Factors related to specific behaviours that are more common among younger people, such as having sex with multiple partners and incorrect condom use, ${ }^{71519}$ and added to a deficient screening for some STIs $^{910}$ may lead eventually to an increase in HIV incidence. Our results show that previous diagnosis of a STI, sexual behaviour 
and number of sexual partners are good predictors of HIV coinfection among young people diagnosed of gonorrhoea, syphilis or LGV that allow identifying them to refer for intervention. Implementing and improving STI/HIV prevention and control programmes that reduce STI in young people are needed to avert future STI and HIV acquisition, especially targeting the most vulnerable persons.

\section{Author affiliations}

${ }^{1}$ Epidemiology Service, Public Health Agency of Barcelona (ASPB), Barcelona, Spain ${ }^{2}$ Preventive Medicine and Public Health Training Unit PSMar-UPF-ASPB (Parc de Salut Mar - Pompeu Fabra University - Agència de Salut Pública de Barcelona), Barcelona, Spain

${ }^{3}$ Hospital de la Vall d'Hebron, Universitat Autònoma de Barcelona, Spain

${ }^{4}$ Hospital Clínic de Barcelona, Universitat de Barcelona, Barcelona, Spain

${ }^{5}$ Hospital del Mar, Universitat Autonòma de Barcelona, Barcelona, Spain

${ }^{6}$ Hospital de la Santa Creu i Sant Pau, Universitat Autònoma de Barcelona,

Barcelona, Spain

${ }^{7}$ Hospital Puigvert, Universitat Autònoma de Barcelona, Spain

${ }^{8}$ Hospital Tries i Pujol, Universitat Autònoma de Barcelona, Badalona, Barcelona,

Spain

${ }^{9}$ CIBER Epidemiología y Salud Pública (CIBERESP), Madrid, Spain

${ }^{10}$ Foundation of Tuberculosis Research Unit of Barcelona, Spain

Acknowledgements We thank all the reporting physicians who have contributed to the collection and quality of the information in the surveys. The Spanish Society of Epidemiology (SEE) for rewarding with 'VII Premio Emilio Perea' the work that gave rise to this article as the second best oral senior communication in the SEE Congress held in Barcelona in September 2017.

Collaborators STI-HIV group of Barcelona: ASPB (Cristina Rius, Sonia Gil, Pilar Gorrindo, Roser Clos, Raquel Sánchez, Miriam Ros, Eva Masdeu, Pere Simon, Maria Jose Santomà), Hospital de la Vall d'Hebron (Pere Armengol, Adrià Curran, Esteve Ribera, Vicenç Falcó), Hospital de la Santa Creu i Sant Pau (Maria Gracia Mateo, M Mar Gutierrez, Pere Domingo, Joaquin López-Contreras), Hospital del Mar (Judit Villar, Ana Guelar,), Hospital Germans Tries i Pujol (Beatriz Mothe), Hospital Clínic de Barcelona (Irene Fuertes, Ana Gonzalez Cordon, José L Blanco, Felipe García, Josep Mallolas, Josep M Miró).

Contributors PGd0 and JC developed the surveillance system for STI. PGdO designed the study, AS and MM carried out the bibliographic search and the statistical analysis. AS, MM, JC, PGdO, MAr, MV, MJB, I0, AG-C, MAI, GM-E, HK, MG, $A V$ and JC interpreted the results. AS and MM prepared the manuscript. STI-HIV group of Barcelona participated in the acquisition and interpretation of the data. AS, MM, JAC, PGdO, MAr, MV, MJB, I0, AG-C, MAI, GM-E, HK, MG, AV, JC and STIHIV group of Barcelona collaborated in the critical review and approved the final manuscript.

Funding The authors have not declared a specific grant for this research from any funding agency in the public, commercial or not-for-profit sectors.

Competing interests None declared.

Provenance and peer review Not commissioned; externally peer reviewed.

Data sharing statement № additional data are available.

Open access This is an open access article distributed in accordance with the Creative Commons Attribution Non Commercial (CC BY-NC 4.0) license, which permits others to distribute, remix, adapt, build upon this work non-commercially, and license their derivative works on different terms, provided the original work is properly cited, appropriate credit is given, any changes made indicated, and the use is non-commercial. See: http://creativecommons.org/licenses/by-nc/4.0/.

\section{REFERENCES}

1. WHO. Sexually transmitted infections (STIs). http://www.who.int/ mediacentre/factsheets/fs110/en/ (accessed 26 Feb 2018).

2. European Centre for Disease Prevention and Control. Sexually transmitted infections in Europe 2013. Stockholm: ECDC, 2015. https://ecdc.europa.eu/sites/portal/files/media/en/publications/
Publications/sexual-transmitted-infections-europe-surveillancereport-2013.pdf.

3. Área de vigilancia del VIH y conductas de riesgo. Vigilancia epidemiológica de las infecciones de transmisión sexual 1995-2015. Madrid: Centro Nacional de Epidemiología/Subdirección General de Promoción de la Salud y Epidemiología - Plan Nacional sobre el Sida, 2017. https://www.msssi.gob.es/en/ciudadanos/enfLesiones/ enfTransmisibles/sida/vigilancia/Vigilancia_ITS_1995_2015.pdf (accessed 8 Aug 2017).

4. Área de Vigilancia de VIH y Comportamientos de Riesgo. Vigilancia Epidemiológica del VIH y sida en España: Sistema de Información sobre Nuevos Diagnósticos de VIH y Registro Nacional de Casos de Sida. Madrid: S.G. de Promoción de la Salud y Epidemiología / Centro Nacional de Epidemiología - Plan Nacional sobre el Sida ISCIII, 2016. https://www.msssi.gob.es/ciudadanos/enfLesiones/ enfTransmisibles/sida/vigilancia/InformeVIH_SIDA_2016.pdf (accessed 22 May 2017).

5. European Centre for Disease Prevention and Control. HIV and AIDS. In: ECDC. Annual epidemiological report for 2015. Stockholm: ECDC, 2017. https://ecdc.europa.eu/sites/portal/files/documents/AER_for_ 2015-HIV-AIDS.pdf (accessed 26 Feb 2018).

6. Martí-Pastor M, García de Olalla P, Barberá MJ, et al. HIV Surveillance Group. Epidemiology of infections by HIV, Syphilis, Gonorrhea and Lymphogranuloma Venereum in Barcelona City: a population-based incidence study. BMC Public Health 2015;15:1015.

7. Gibson EJ, Bell DL, Powerful SA. Common sexually transmitted infections in adolescents. Prim Care 2014;41:631-50.

8. Harden A, Brunton G, Fletcher A, et al. Teenage pregnancy and social disadvantage: systematic review integrating controlled trials and qualitative studies. BMJ 2009;339:b4254.

9. Yavorsky RL, Hollman D, Steever J, et al. Prevalence of sexually transmitted infections in at-risk adolescent females at a comprehensive, stand-alone adolescent health center in New York City. Clin Pediatr 2014;53:890-5.

10. O'Connor CA, Shubkin CD. Adolescent STIs for primary care providers. Curr Opin Pediatr 2012;24:647-55.

11. Newbern EC, Anschuetz GL, Eberhart MG, et al. Adolescent sexually transmitted infections and risk for subsequent HIV. Am J Public Health 2013;103:1874-81.

12. Mullins TL, Rudy BJ, Wilson CM, et al. Incidence of sexually transmitted infections in HIV-infected and HIV-uninfected adolescents in the USA. Int J STD AIDS 2013;24:123-7.

13. Generalitat de Catalunya Departament de Salut. Definició de cas de les malalties de declaració obligatòria. 2010 (Accessed 9 Aug 2017).

14. Ajuntament de Barcelona. Población de Barcelona por grandes grupos de edad. Evolución 1981-2015. http://www.bcn.cat/ estadistica/castella/dades/inf/lecpadro/lec15/part1/t21.htm (Accessed 13 Oct 2016).

15. Adolescents and Young Adults | Prevention | STDs | CDC. https:// www.cdc.gov/std/life-stages-populations/adolescents-youngadults. htm (Accessed 15 Sep 2017).

16. Bartoll X, Salvador M, Allué N, et al. Enquesta de salut de Barcelona 2011. Barcelona: Agència de Salut Pública de Barcelona, 2013. https://www.aspb.cat/documents/enquesta-salut-barcelona-2011resultats-principals/.

17. Decret $67 / 2010$, de 25 de maig, pel qual es regula el sistema de notificación de malalties de declaració obligatòria i brots epidèmics al Departament de Salut. DOGC. Diari Oficial de la Generalitat de Catalunya, 8 Juliol 2010; núm. 5666. http://cido.diba.cat/legislacio/ 1342856/decret-672010-de-25-de-maig-pel-qual-es-regula-elsistema-de-notificacio-de-malalties-de-declaracio-obligatoria-ibrots-epidemics-al-departament-de-salut.

18. Rose S. International ethical guidelines for epidemiological studies: by the Council for International Organizations of Medical Sciences (CIOMS). Am J Epidemiol 2009;170:1451-2.

19. Dehne KL, Riedner G. Sexually transmitted infections among adolescents the need for adequate health services. http://www.who. int/child-adolescent-health (Accessed 24 Aug 2017).

20. European Centre for Disease Prevention and Control. Lymphogranuloma venereum. In: Annual epidemiological report for 2015. Stockholm: ECDC, 2017.

21. European Centre for Disease Prevention and Control. Syphilis. In: Annual epidemiological report for 2015. Stockholm: ECDC, 2017.

22. European Centre for Disease Prevention and Control. Gonorrhoea. In: Annual epidemiological report for 2015. Stockholm: ECDC, 2017.

23. Estadístiques de Salut. Morbiditat per malalties de declaració obligatòria a Barcelona ciutat. 2015 https://www.aspb.cat/wpcontent/uploads/2017/11/Morbiditat_per_malalties declaracio obligatoria_Barcelona_2015.pdf (Accessed 29 Jul 2018). 
24. Hughes G, Field N. The epidemiology of sexually transmitted infections in the UK: impact of behavior, services and interventions. Future Microbiol 2015;10:35-51.

25. Patterson-Lomba O, Goldstein E, Gómez-Liévano A, et al. Per capita incidence of sexually transmitted infections increases systematically with urban population size: a cross-sectional study. Sex Transm Infect 2015;91:610-4.

26. Davoren MP, Hayes K, Horgan M, et al. Sexually transmitted infection incidence among adolescents in Ireland. J Fam Plann Reprod Health Care 2014;40:276-82.

27. Public Health Wales. Public Health Wales HIV and STI trends in Wales HIV and STI trends in Wales. 2013 http://www.hps.scot.nhs. uk/ (Accessed 2 Jan 2019).

28. Forhan SE, Gottlieb SL, Sternberg MR, et al. Prevalence of sexually transmitted infections among female adolescents aged 14 to 19 in the United States. Pediatrics 2009;124:1505-12.

29. van der Bij AK, Stolte IG, Coutinho RA, et al. Increase of sexually transmitted infections, but not HIV, among young homosexual men in Amsterdam: are STIs still reliable markers for HIV transmission? Sex Transm Infect 2005;81:34-7.
30. Tarr ME, Gilliam ML. Sexually transmitted infections in adolescent women. Clin Obstet Gynecol 2008;51:306-18.

31. van den Broek IV, Verheij RA, van Dijk CE, et al. Trends in sexually transmitted infections in the Netherlands, combining surveillance data from general practices and sexually transmitted infection centers. BMC Fam Pract 2010;11:39.

32. Mulhall BP, Wright ST, De La Mata N, et al. Risk factors associated with incident sexually transmitted infections in HIV-positive patients in the Australian HIV Observational Database: a prospective cohort study. HIV Med 2016;17:623-30.

33. Recomendaciones sobre Profilaxis Pre-Exposición en adultos para la Prevención de la Infección por VIH en España. AIDS Study Group (GeSIDA) of the Spanish Society of Infectious Diseases and Clinical Microbiology. http://www.cesida.org/wp-content/uploads/2013/ 09/gesida-guiasclinicas-2016-profilaxis_pre-exposicionVIH.pdf (Accessed 26 Dec 2018).

34. Peterman TA, Carter MW. Effective interventions to reduce sexually transmitted disease. Sex Transm Dis 2016;43:S1-S2. 